\title{
Analysis of spheroidized AISI 1050 steel in terms of cutting forces and surface quality
}

\author{
Ş. Baday ${ }^{1}$, H. Başak ${ }^{2 *}$, A. Güral ${ }^{3}$ \\ ${ }^{1}$ Şrnak University, Şırnak Vocational School, 73000, Şırnak, Turkey \\ ${ }^{2}$ Gazi University, Technology Faculty, Department of Industrial Design, 06500 Teknikokullar, Ankara, Turkey \\ ${ }^{3}$ Gazi University, Technology Faculty, Department of Metallurgical and Materials Engineering, \\ 06500 Teknikokullar, Ankara, Turkey
}

Received 20 May 2015, received in revised form 9 December 2015, accepted 10 December 2015

\begin{abstract}
In this study, the effects of microstructure differences obtained with the application of different spheroidizing heat treatment cycles on medium carbon steel on cutting forces and surface roughness values were investigated. For this purpose, a group of AISI 1050 materials was annealed at $700^{\circ} \mathrm{C}$ below $A_{\mathrm{c} 1}$ temperature for $720 \mathrm{~min}$ and cementite phases were spheroidized by the traditional method. Another group of materials was quenched after austenitization at $850^{\circ} \mathrm{C}$ for $15 \mathrm{~min}$ and then cementites were spheroidized in the ferrite matrix by over-tempering separately at $600{ }^{\circ} \mathrm{C}$ for 15 and $60 \mathrm{~min}$ and at $700^{\circ} \mathrm{C}$ for $60 \mathrm{~min}$. Machining of the samples was tested under dry cutting conditions in CNC turning center with SNMG 120408 cementite carbide cutting tool and proper PSBNR 2525M12 tool holder with 75-degree edge angle. Cutting forces of traditionally spheroidized samples were lower than the samples spheroidized after quenching. In addition, their cutting forces decreased due to the increase in the average sizes of spheroidal cementite. Minimum surface roughness value was obtained from the samples which were spheroidized at $600^{\circ} \mathrm{C}$ for $15 \mathrm{~min}$ after quenching. However, surface roughness rate of the sample increased as spheroidizing time increased.
\end{abstract}

K e y w or d s: spheroidizing, cutting forces, surface roughness, medium carbon steel

\section{Introduction}

Due to the lamellar cementite phases they contain, the machinability and formability of medium and high carbon steels are quite difficult, and they increase the cost. Therefore, their ductility, impact toughness, fatigue and machining behavior can significantly be improved with spheroidizing heat treatment which is conducted with long-time annealing about at $A_{\mathrm{c} 1}$ (eutectoid transformation) temperatures [1]. On the other hand, cementite phases can also be spheroidized by over-tempering martensite phase at a high temperature which is produced from austenite by quenching at high temperature $[2,3]$. The reason for this is that many potential nucleations are ensured in the martensite lath boundaries as the tempering heat rises and with the fast diffusion of carbon as the rapid formation of stable cementite type carbide is ensured, and they are formed spheroidally to decrease the surface tension. As a result of this process, the tensile strength of the steel decreases to some extent, ductility reduces and above all, toughness and machinability of the steel can significantly be increased. These spheroidal cementite pieces are easier to form by tempering generally at about $700^{\circ} \mathrm{C}$ in medium carbon steel [4]. Many researchers state that the microstructure of spheroidizing heat treated steel shows similarity to the microstructure of martensite over-tempered at high temperatures [5]. Quenched and tempered steels are commonly used in the production of gear wheels, axle shafts and spindle arms which are various automobile parts and in parts having a high degree of abrasive wear $[6,7]$.

Phases that are in the microstructure of steel have a significant effect on the machinability of materials. Spheroidized pearlite structure gives better machin- 
Table 1. Chemical composition of AISI 1050 material used in the studies (wt.\%)

\begin{tabular}{cccccc}
\hline $\mathrm{C}$ & $\mathrm{Si}$ & $\mathrm{Mn}$ & $\mathrm{P}$ & $\mathrm{S}$ & $\mathrm{Cr}$ \\
\hline 0.52 & 0.28 & 0.81 & 0.009 & 0.022 & 0.08 \\
\hline $\mathrm{Mo}$ & $\mathrm{Ni}$ & $\mathrm{Al}$ & $\mathrm{Cu}$ & $\mathrm{Sn}$ & $\mathrm{Fe}$ \\
\hline 0.02 & 0.10 & 0.020 & 0.17 & 0.011 & Remainder \\
\hline
\end{tabular}

Table 2. Heat treatments applied to the samples

\begin{tabular}{cl}
\hline Sample codes & Heat treatment parameters \\
\hline T $600-15$ & Austenitization at $850^{\circ} \mathrm{C}$ for $15 \mathrm{~min}+$ quenching + tempering at $600^{\circ} \mathrm{C}$ for $15 \mathrm{~min}$ \\
$\mathrm{~T} 600-60$ & Austenitization at $850^{\circ} \mathrm{C}$ for $15 \mathrm{~min}+$ quenching + tempering at $600^{\circ} \mathrm{C}$ for $60 \mathrm{~min}$ \\
$\mathrm{~T} 700-60$ & Austenitization at $850^{\circ} \mathrm{C}$ for $15 \mathrm{~min}+$ quenching + tempering at $700^{\circ} \mathrm{C}$ for $60 \mathrm{~min}$ \\
$\mathrm{D} 700-720$ & Directly isothermal annealing at $700^{\circ} \mathrm{C}$ for $720 \mathrm{~min}$ \\
\hline
\end{tabular}

ability results than lamellar perlitic structure. In AISI 4120 steel, the best machinability was observed in terms of the expendability of the chip under milled conditions having ferrite + bainite structure. Also, the lowest surface roughness value was obtained under conditions which were quenched and tempered in lower cutting speed and feed amount and when spheroidizing process was applied, as the time of spheroidizing increased, surface roughness also increased. In another study, surface roughness values of AISI 1040 steel increased with spheroidizing temperature and time increase. Surface roughness values also increased with feed rate increase in these steels. Surface roughness was detected to increase as the result of soft ferrite phase's separation by a ductile fracture in machining of medium carbon steels $[8,9]$.

In this study, the effects of the pieces spheroidized by over-tempering AISI 1050 steel at various temperatures and times after quenching by traditional spheroidizing heat treatment on the cutting forces and surface roughness after machining were investigated.

\section{Material and method}

AISI 1050 steel that was chosen as the proper material and whose chemical composition is given in Table 1 and microstructure is given in Fig. 1 was used. According to the SEM microstructure of this material, it consists of a fine lamellar perlitic structure that has $20 \mu \mathrm{m}$ average column length in the primer ferritic matrix. $\varnothing 30 \times 200 \mathrm{~mm}^{2}$ sized samples were prepared from this material to be used in machinability tests.

Some of these samples were austenizated first at $850^{\circ} \mathrm{C}$ for $15 \mathrm{~min}$ and then quenched in water to produce martensite phase. Then they were respectively treated with isothermal annealing at $600{ }^{\circ} \mathrm{C}$ for 15 and $60 \mathrm{~min}$ and at $700^{\circ} \mathrm{C}$ for $60 \mathrm{~min}$ separately, and

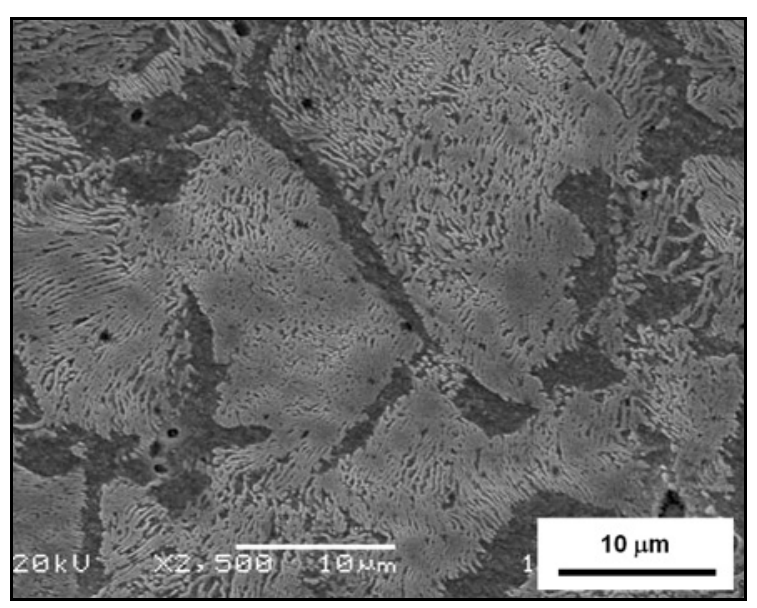

Fig. 1. Microstructure of AISI 1050 material.

spheroidal cementite with various shapes and morphology was produced in a ferritic matrix. The other samples were traditionally spheroidizing heat treated. For this purpose, they were treated with isothermal annealing right below $A_{\mathrm{c} 1}$ eutectoid transformation temperature at $700{ }^{\circ} \mathrm{C}$ for $720 \mathrm{~min}$ and slowly cooled in the furnace. The summary of heat treatments applied to the samples is given in Table 2 with sample codes.

For microstructure examination, the samples were prepared by standard metallographic methods for metallographic examinations. $2 \%$ Nital was used as the etchant for revealing the microstructure. Jeol 6060 JSM-LV Scanning Electron Microscope (SEM) was used for imaging the microstructures. Hardness measurements of the samples were detected in Vickers value with Intron-Wolpert hardness tester by loading $30 \mathrm{~kg}$.

In accordance with the test conditions specified in 
ISO 3685, cementite carbide cutting tool in SNMG form and proper PSBNR 2525M12 tool holder with 75-degree edge angle were used in machining tests. Double sided cutting tool in the quality of CVD plated GC4215 was chosen as the appropriate machining material. SNMG 120408 PM chip breaker geometry of the tool producer firm was chosen as the cutting tool. Tests were performed in CNC turning center under dry cutting conditions. Kistler 9275B type dynamometer with a capacity of triaxial measurement was used for cutting force measurements.

Machining tests were carried out according to ISO 3685 and the data of tool producer firm. 150, 175, 200 and $250 \mathrm{~m} \mathrm{~min}^{-1}$ were chosen as the cutting speeds, 0.16 and $0.25 \mathrm{~m} \mathrm{rev}^{-1}$ as feed rate and $2.5 \mathrm{~mm}$ as the cutting depth. A new cutting tool was used in each application to provide the same conditions for each test. Mitutoyo Surftest SJ-201 portable surface roughness tester was used for surface roughness measurements. Surface roughness values were tested from three different spots of each samples' machined surface, and the average value was determined.

\section{Test results and discussion}

\subsection{Microstructure}

Cementite microstructures spheroidized in a ferritic matrix in T600-15, T600-60, T700-60 samples after quenching and at the end of various spheroidizing temperatures and times are shown in Fig. 2 as cementite microstructures spheroidized in a ferritic matrix in D700-720 sample ensured with traditional method directly. Isothermal annealing below $A_{\mathrm{c} 1}$ eutectoid transformation temperature at $700^{\circ} \mathrm{C}$ for $12 \mathrm{~h}$ is shown in Fig. 3.

In the microstructure of T600-15 sample (Fig. 2a), it is seen that nano-sized rod-like cementite which extended across martensite lath boundaries started to spheroidize but did not spheroidize completely. As seen in Fig. 2b,c, this spheroidizing effect appears more in the microstructures of T600-60 and T700-60. It is clearly seen in Fig. 2 that cementite phases spheroidized more effectively with the increase of temperature and time after quenching, but their average sizes increased. Martensite phase obtained after quenching has lower free energy and tends to form steadier cementite phases. In addition, martensite plate boundaries are quite suitable places for nucleation of cementite phases due to its high absence of dislocation and low activation energy. Therefore, the morphology of spheroidal cementite phases formed in the T600-15 sample is acicular, and it is like the lath boundaries of previous martensite (Fig. 2a). Acicular cementite phases nucleated with increased spheroidizing time and temperature in T600-60 and T700-60
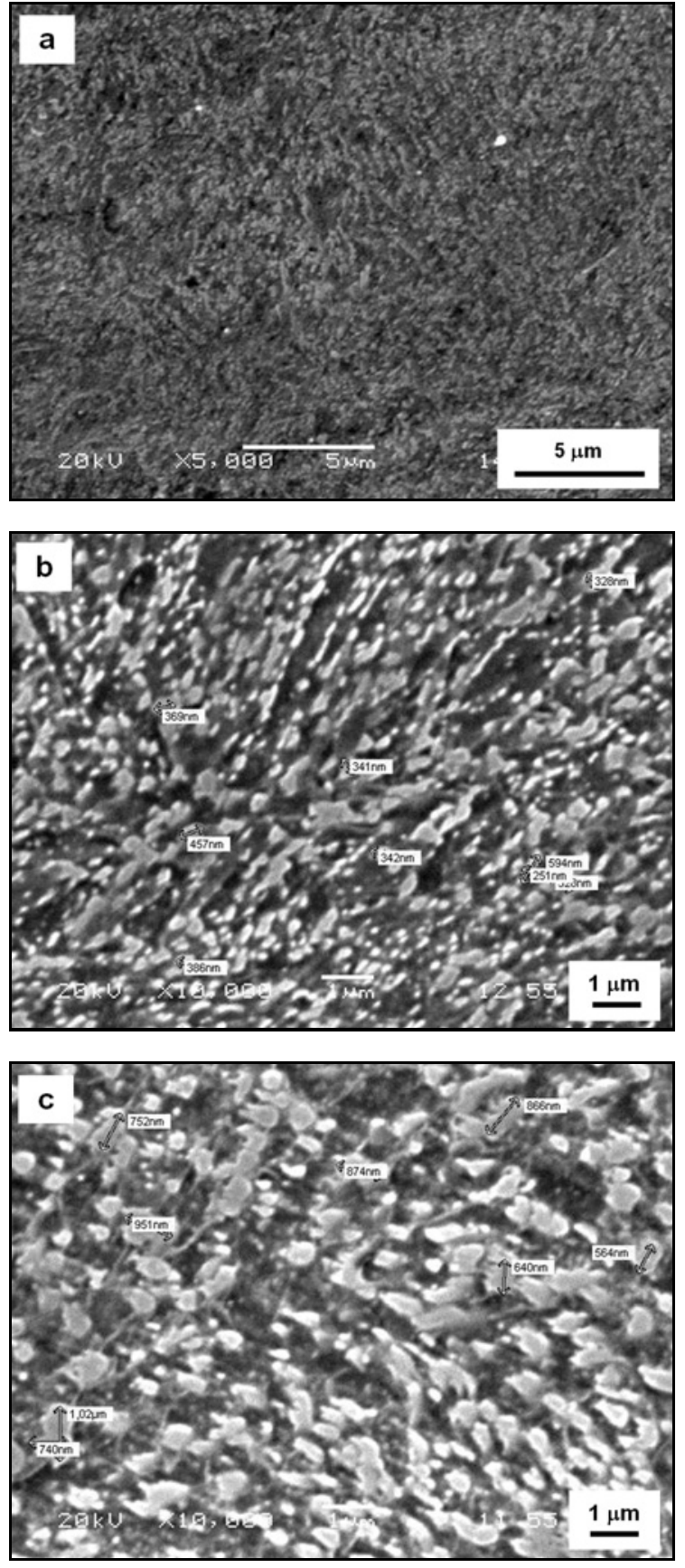

Fig. 2. SEM microstructures of samples that were spheroidized after quenching (a) T600-15, (b) T600-60, (c) T700-60 .

samples started to form into a spheroidal morphology to ease surface tension.

As seen in Fig. 3, when SEM microstructure of D700-720 sample that was spheroidizing heat treated with isothermal annealing at $700^{\circ} \mathrm{C}$ for $12 \mathrm{~h}$ is analyzed it is seen that spheroidized cementite particles spread in previous pearlite colonies with secondary ferritic areas and there is no spheroidal cementite in 


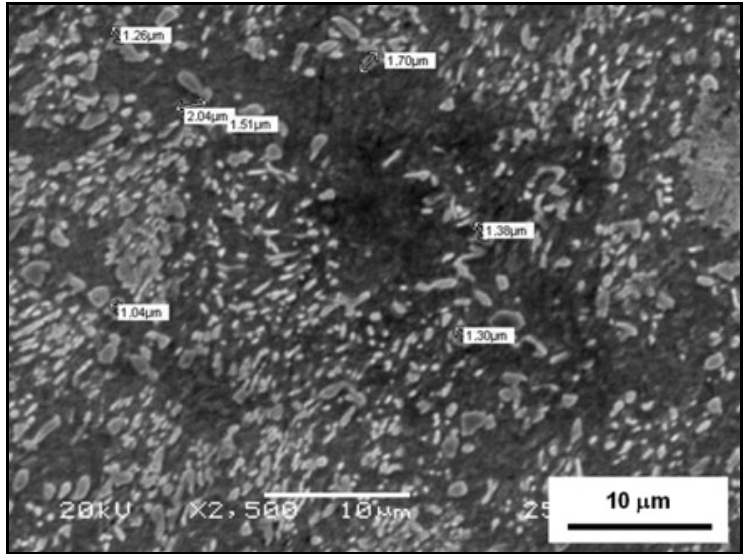

Fig. 3. SEM microstructure of traditionally spheroidized sample D700-720.

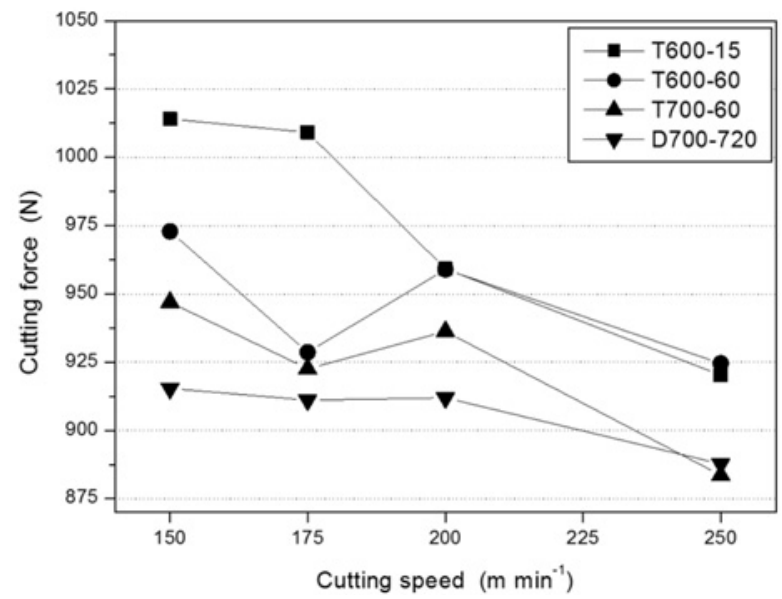

Fig. 4. Main cutting forces measured depending on the cutting speed in $0.16 \mathrm{~mm} \mathrm{rev}^{-1}$ feed rate.

primer ferritic areas. It was also detected that cementite phases did not spheroidize in pearlite colonies in some areas.

When the average sizes of spheroidal cementite obtained from various spheroidizing heat treatment cycles of sample AISI 1050 were compared, the average cementite particle size was found as $300-400 \mathrm{~nm}$ in sample series T600-15 and T600-60, about $600 \mathrm{~nm}$ in sample series T700-60 and the range of $1.5-2 \mu \mathrm{m}$ in sample D700-720. The basic reason of thinner cementite phase formation in sample series T than D700-720 is that while numerous cementite nucleated in martensitic areas, cementite lamellas fragmented to ease the surface tension without a new nucleation for the formation of spheroidal cementite in sample D700-720. Another reason is that the spheroidizing time in sample series $\mathrm{T}$ is less than in sample D700-720.

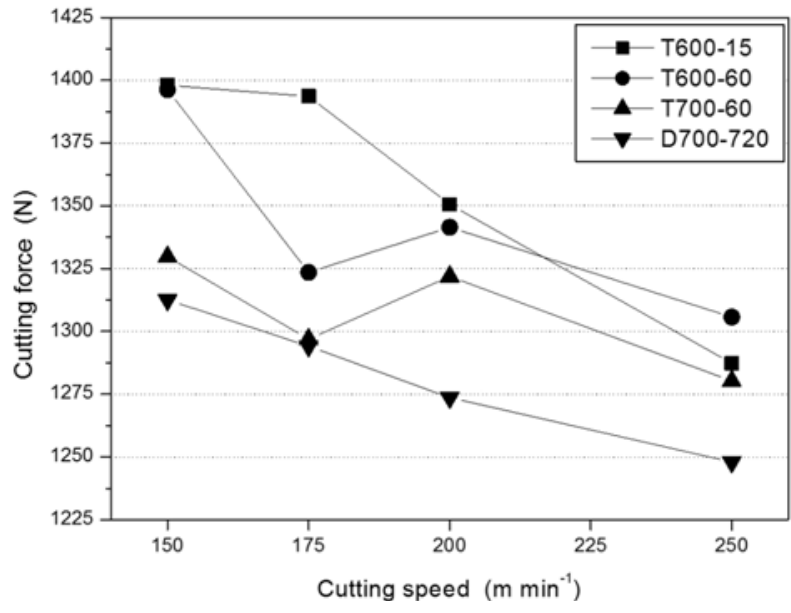

Fig. 5. Main cutting forces measured depending on the cutting speed in $0.25 \mathrm{~m} \mathrm{rev}^{-1}$ feed rate.

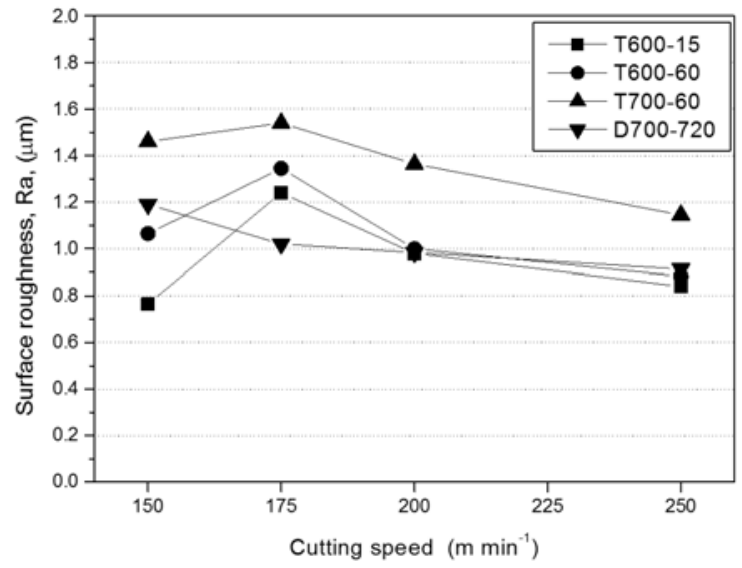

Fig. 6. Surface roughness measured depending on cutting speed in $0.16 \mathrm{~mm} \mathrm{rev}^{-1}$ feed rate.

\subsection{Cutting forces}

Main cutting force values that were measured regarding cutting speeds and feed rates of the samples are given in Figs. 5 and 6 . It can be said that with the increase of cutting speed, cutting forces decrease in general. The decrease of cutting force due to the increasing cutting speed can be explained by the decrease of the contact area of cutting tool and chips rake face because of the temperature increase and partially with the decrease of shear stress in the flowage area of chips (second deformation area). And another reason is the decrease of friction coefficient in cutting tool/chips interface because of the increased temperature in cutting tool/chips interface [10].

The highest cutting force is obtained from sample T600-15, and these values decreased respectively in samples T600-60, T700-60, and D700-720. This cir- 
cumstance was seen to be related to hardness values of the samples. As in this study the hardness values obtained from samples T600-15, T600-60, T700-60, D700-720 are found respectively as: $361 \pm 6,268 \pm 7$, $237 \pm 17$, and $212 \pm 12$ HV30. On the other hand, spheroidal cementite particles obtained from the samples can be considered to be effective. Cementite particles might be broken more easily during chip removal with the decrease of their size, and this might have an effect on chip breaking. Besides, cementite particles' constant increase with spheroidizing temperature increase in quenched samples and formation of larger ferrite areas as a result of carbide uniting may have decreased cutting forces. In addition, as the sizes of spheroidized carbides increase, Ferrite $/ \mathrm{Fe}_{3} \mathrm{C}$ may become incompatible and may ease the disintegration of chips from the material. For this reason, it is considered that lower main cutting speeds were obtained from traditionally spheroidizing heat treated sample D700-720.

However, it is seen that cutting forces of T600-60 and T700-60 samples for $175 \mathrm{~m} \mathrm{~min}^{-1}$ cutting speed are lower than $200 \mathrm{~m} \mathrm{~min}^{-1}$. Formation of built-up edge (BUE) in chip roots during chip removal can be a logical explanation for this. The increase of BUE tendency caused the increase of active rake while decreasing the tool chips contact length and cutting forces.

BUE tendency is frequently seen in metals that are soft and have a high potential of plastic deformation. It was considered that BUE was not formed in the sample D700-720 which has the lowest hardness value since the pearlitic areas in which spheroidizing was not completed in the microstructure of this sample may have restricted the plastic deformation potential of the sample and may have a chip breaker effect before the formation of BUE during chip removal, which is confirmed by the low cutting forces of this sample.

With the increase of feed rate from $0.16 \mathrm{~mm} \mathrm{rev}^{-1}$ (Fig. 4) to $0.25 \mathrm{~mm} \mathrm{rev}^{-1}$ (Fig. 5), an increase of $40 \%$ on average was seen in cutting forces. "Chip cross section area" formed depending on the feed rate and cutting depth is the most important factor that determines main cutting force. Accordingly, chip cross section that increases with feed rate increase is the main reason for cutting force increase.

\subsection{Surface roughness}

Changes in surface roughness measured depending on the cutting parameters of the samples are given in Figs. 6 and 7. A decrease in the surface roughness value is generally seen in every sample when cutting speed increases. The most common method used in the literature is to increase the cutting speed to improve surface roughness value. Improving surface roughness with increasing cutting speed can be explained with easier deformation process depending on the increas-

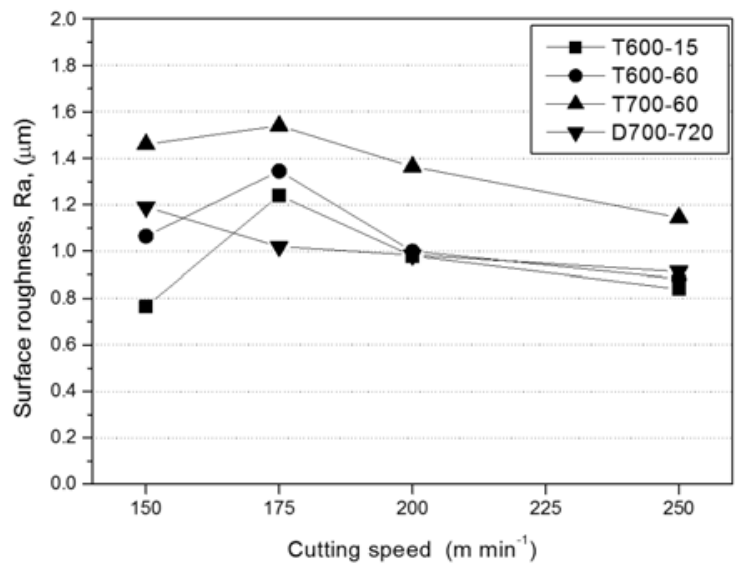

Fig. 7. Surface roughness measured depending on cutting speed in $0.25 \mathrm{~mm} \mathrm{rev}^{-1}$ feed rate.

ing temperature in high speeds, easy deformation of workpiece material around cutting edge and nose radius and flowage area that is formed at these high temperatures. In addition, the easily deformed material can be formed during machining without tearing and accordingly an improvement is seen in the surface quality of the workpiece [11].

In other words, the decrease of surface roughness with the increase of cutting speed can be explained with the BUE whose formation decreases at high cutting speeds. But an increase of surface roughness values was observed in $175 \mathrm{~m} \mathrm{~min}^{-1}$ cutting speed. The reason for this increase is the BUE formation that occurred in high and medium cutting forces in ductile materials. When the microstructures of chips taken from the samples are analyzed, the BUE formation is clearly seen (Fig. 6).

According to Figs. 6 and 7, it is seen that when feed rate increases, surface roughness also increases in each sample. Increase or decrease of feed rate directly affects surface roughness value. Therefore, as the feed rate increases, surface roughness value will also increase and accordingly surface quality will decrease.

It was seen that the surface roughness values of sample T600-15 were lower. That could be attributed to the higher homogeneity of the microstructure of the sample tempered in a short time. The increase of heat treatment time negatively affects surface roughness values of workpieces. The increase in the diffusion speed of carbon depending on the increase in tempering temperature, fast growth and unification of carbides and consequently the formation of larger ferritic areas that increase surface roughness values can explain the lower value in this sample.

The SEM images of chips taken from $600 \mathrm{~T}-60 \mathrm{sam}-$ ple at $2.5 \mathrm{~mm}$ cutting depth, $0.16 \mathrm{~mm} \mathrm{rev}^{-1}$ feed and 175 and $200 \mathrm{~m} \mathrm{~min}^{-1}$ cutting speed are seen in Fig. 8. When the amount of adhesive chips shown in Fig. 8a 

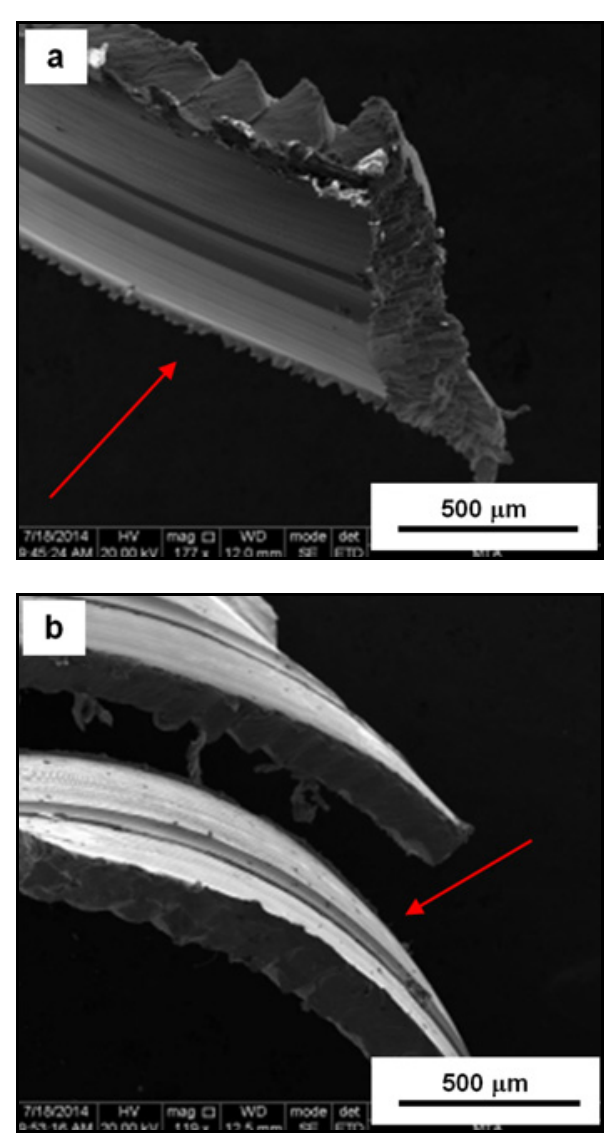

Fig. 8. SEM image of chips formed in machining of sample $\mathrm{T} 600-60$ at (a) $175 \mathrm{~m} \mathrm{~min}^{-1}$, (b) $200 \mathrm{~m} \mathrm{~min}^{-1}$ cutting speeds.

with the red arrow is compared with the amount in Fig. $8 \mathrm{~b}$, the increase in the cutting speed indicates that the BUE formation in this material decreased depending on the temperature increase between tool/chips.

\section{Results}

In this study, the changes occurred in microstructure as a result of different spheroidizing heat treatment cycles on AISI 1050 steel, in cutting forces and surface roughness during machining were compared and the obtained results were summarized as below.

- Spheroidal cementite formed in a ferritic matrix that was obtained by over-tempering after quenching in a shorter time when compared to traditional spheroidizing processes and cementite particles sizes also increased depending on the increased spheroidizing time and temperature. Even in the material traditionally spheroidized at $700{ }^{\circ} \mathrm{C}$ for $720 \mathrm{~min}$ non-spheroidized perlitic areas were observed.
- The highest cutting force was obtained for the sample T600-15, and these values decreased respectively in T600-60, T700-60, and D700-720, which could be attributed to the hardness values of the samples.

- Surface roughness values of the samples spheroidized after quenching were found to be lower than the sample traditionally spheroidized and the lowest surface roughness values were obtained for tempered material T600-15.

- The BUE formed in the tool cutting edge during the machining increases the surface roughness value since it is unstable. Therefore, when chip remains are big and unstable in low cutting speeds, surface roughness increases more, and a worse surface is formed.

\section{References}

[1] Can, A. Ç.: Material Information for Design Engineers. Istanbul, Birsen Publishing 2006.

[2] Hoseiny, H., Klement, U., Sotskovszki, P., Andersson, J.: Materials and Design, 32, 2011, p. 21. doi:10.1016/i.matdes.2010.06.045

[3] Podder, A. N., Bhadeshia, H. K. D. H.: Materials Science and Engineering A, 527, 2010, p. 2121. doi:10.1016/j.msea.2009.11.063

[4] Andres, C. G., Caruana, G., Alvarez, L. F.: Materials Science and Engineering A, 241, 1998, p. 211. doi:10.1016/S0921-5093(97)00491-7

[5] Zhang, M. X., Kelly, P. M.: Acta Materialia, 46, 1998, p. 408. doi:10.1016/S13596454(98)00046-9

[6] Lucey, T., Wuhrer, R., Moran, K., Reid, M., Huggett, P., Cortie, M.: Journal of Materials Processing Technology, 212, 2012, p. 2349. doi:10.1016/j.jmatprotec.2012.06.025

[7] Hintikka, J., Lehtovaara, A., Mäntylä, A.: Tribology International, 94, 2016, p. 633. doi:10.1016/j.triboint.2015.10.029

[8] Katayama, S., Toda, M.: Journal of Materials Processing Technology, 62, 1996, p. 358. doi:10.1016/S0924-0136(96)02435-1

[9] Ljustina, G., Larsson, R., Fagerström, M.: Finite Elements in Analysis and Design, 80, 2014, p. 1. doi:10.1016/j.finel.2013.10.006

[10] Zhou, L., Peng, F. Y., Yan, R., Yao, P. F., Yang, C. C., Li, B.: International Journal of Machine Tools and Manufacture, 97, 2015, p. 29. doi:10.1016/j.ijmachtools.2015.07.001

[11] Hagiwara, M., Chen, S., Jawahir, I. S.: Journal of Materials Processing Technology, 209, 2009, p. 332. doi:10.1016/j.jmatprotec.2008.02.023 